\title{
Study of the Effect of Gas Nitriding Time on Microstructure and Wear Resistance of 42CrMo4 Steel
}

\author{
Mohamed Ali Terres, Lotfi Ammari, Abdelkarim Chérif \\ Laboratory Mechanics, Materials and Processes (LMMP) ENSIT, University of Tunis, Tunis, Tunisia \\ Email: mohamedali_terres@yahoo.fr
}

How to cite this paper: Terres, M.A. Ammari, L. and Chérif, A. (2017) Study of the Effect of Gas Nitriding Time on Microstructure and Wear Resistance of $42 \mathrm{CrMo} 4$ Steel. Materials Sciences and Applications, 8, 493-507.

https://doi.org/10.4236/msa.2017.86034

Received: April 15, 2017

Accepted: June 19, 2017

Published: June 22, 2017

Copyright $\odot 2017$ by authors and Scientific Research Publishing Inc. This work is licensed under the Creative Commons Attribution International License (CC BY 4.0).

http://creativecommons.org/licenses/by/4.0/

\begin{abstract}
Prior studies have noted that gas nitriding has a considerable effect for wear resistance. The aim of this paper is to study the influence of gas nitriding time $(12,24,36$ and $48 \mathrm{~h})$ in the wear behaviour of $42 \mathrm{CrMo} 4$ steel. It has been assessed by micro hardness, pin-on-disc tribosystem, and SEM through the nitrided layer for each nitriding time. The study relates to the performance of the compound layer and the diffusion layer with respect to adhesive wear. The results were analyzed in terms of the weight lost during wear, for nitrided steel with and without the compound layer, and for untreated steel. It has been observed that wear rate varies as a function of the tests conditions due to the presence of different wear mechanisms. Thus, for short tests conditions wear rate depends on two mechanisms: plastic deformation and adhesive wear, whereas for large tests conditions the mechanisms controlling wear rate are abrasive and oxidative wear. Furthermore, this study contains an analysis of the wear mechanisms of a nitrided part, founded on scanning electron microscopy (SEM) observations of the wear traces at various stages of the evolution of wear. The SEM examination of worn surfaces revealed signatures for the adhesion, abrasion, delamination and tribochemical (oxidative) modes of wear. This is an important issue for future research.
\end{abstract}

\section{Keywords}

Gas Nitriding, 42CrMo4 Steel, Hardening, Wear Rate, Wear Mechanisms, Adhesive Wear

\section{Introduction}

Nitriding process is a chemical-heat treatment consists in introducing nitrogen into metallic materials to improve their surface hardness, fatigue life, wear and corrosion resistance [1] [2] [3]. In engineering the depth of nitriding is generally 
about $0.3-0.4 \mathrm{~mm}$; this thin harder surface layer may cause surface layer spall from matrix because of high-applied load or great stress gradient in surface layer [3] [4] [5] [6].

During nitriding, two different structures are formed from surface to core, known as the compound layer and diffusion region. Wear characteristics of the compound layer depend on many factors such as composition $\varepsilon / \gamma$ ), thickness and mode of mechanical loading [7] [8] [9] [10]. The principal reasons why the surface of steel benefits from nitriding, are the fact that wear and friction properties are improved by structure and microstructure modification, especially via a hardness increase due to the formation of an interstitial solid solution or compound layer [11] [12] [13] [14]. The parameters governing the wear resistance are multiply depending on relative speed, contact pressure, lubricant, and properties of the material itself (hardness surface and residual stress) [15] [16] [17] [18] [19].

The purpose of this work is to study the tribological properties of gas-nitrided $42 \mathrm{CrMo} 4$ steel, and to determine the influence of the compound and diffusion layers on wear behavior. $42 \mathrm{CrMo} 4$ steel is gas-nitrided under different time (12, 24,36 and $48 \mathrm{~h}$ ). The effects on tribological properties of the structure formed after gas nitriding are investigated using a pin-on-disk wear test, micro hardness tester, and scanning electron microscopy (SEM).

\section{Experimental Details}

\subsection{Material and Techniques}

The material used in this study was a 42CrMo4 low-alloy steel with the following composition (wt\%): $0.41 \% \mathrm{C}$; $0.77 \% \mathrm{Mn} ; 0.28 \% \mathrm{Si} ; 1.02 \% \mathrm{Cr} ; 0.16 \% \mathrm{Ni} ; 0.16 \%$ Mo; $0.25 \% \mathrm{Cu}$ and balance Fe. The material was quenched at $850^{\circ} \mathrm{C}$, cooled in oil and tempered at $580^{\circ} \mathrm{C}$. The metallurgical structure obtained is a tempered martensite.

Cylindrical samples $(15 \mathrm{~mm} \times 16 \mathrm{~mm})$ were cut out and rectified under identical conditions to obtain a uniform surface quality for all the studied parts. The average roughness $\left(R_{\mathrm{a}}\right)$ was $0.5 \mu \mathrm{m}$. One series of specimens were submitted to surface treatment by gas nitriding (temperature $(\theta n)=525^{\circ} \mathrm{C}$; Ammonia dissociation degree $(\tau)=35 \%)$ under different time $(12,24,36$ and $48 \mathrm{~h})$.

Nitrided layer were observed by using a scanning electron microscope (SEM) and X-ray diffraction (XRD). Investigations of compound layer were carried out using a Siemens Analytical D5000 diffractometer with $C u$ anode. The $H V_{0.05}$ micro hardness profile of the nitrided layers was obtained in the transverse section by means of Dhimadzu MMV-2 instrument. Three indentations were placed into the compound layer at equal depth in order to define the micro hardness profiles. Residual stress measurements were obtained using the X-ray diffraction method. The diffraction conditions are reported in Table 1.

\subsection{The Tribosystem}

The experimental set-up used to investigate wear significantly affects the me- 
chanisms of wear recorded later on. The device used in this work is based on the initial by linear cylinder/plan contact represented in Figure 1; it is frequently seen in industrial applications such as cams, push rods and rollers. This configuration induces adhesive wear. The cylinder of diameter $200 \mathrm{~mm}$ is made from $\mathrm{X} 200 \mathrm{CrMoV} 12$ steel. The parameters considered are:

- The normal loading $\left(50 \mathrm{~N}<F_{\mathrm{N}}<225 \mathrm{~N}\right)$ and relative speed $(3.1 \mathrm{~m} / \mathrm{s}<V<$ $8.3 \mathrm{~m} / \mathrm{s}$ ) which are two energy parameters that influence the response of the material.

- The nature of the surface layer. Three distinct surface qualities were studied: untreated $42 \mathrm{CrMo} 4$ steel, treated steel with its compound layer, and treated steel without a compound layer. This layer was eliminated by grinding.

The weight loss was measured by weighing with a command precision of $10^{-4}$ g. All measurements were carried out under dry conditions. During each test the friction coefficient was recorded. Finally, the worn surface of nitrided samples was characterized by scanning electron microscope "SEM" observations to investigate the wear mechanisms.

\section{Results}

\subsection{Micro Structural Characterization}

Vickers micro hardness was evaluated at the cross-section of the specimens for

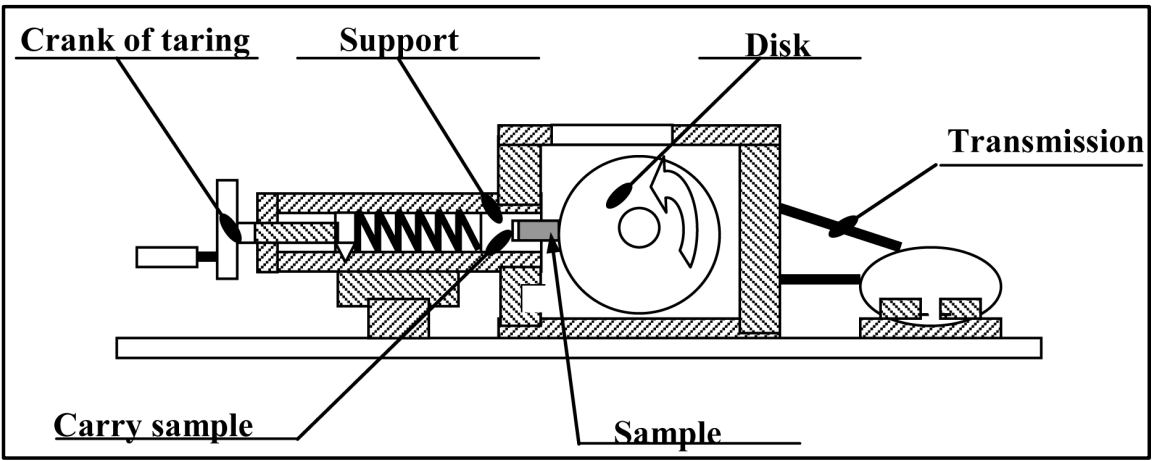

Figure 1. Tribosystem and used specimen geometry.

Table 1. X-ray diffraction conditions.

\begin{tabular}{cc}
\hline Target & $\mathrm{Cr}$ \\
\hline Wavelength $\left(\mathrm{A}^{\circ}\right)$ & 2.2897 \\
Filter & $\mathrm{V}$ \\
Current $(\mathrm{mA})$ & 5 \\
Voltage $(\mathrm{kV})$ & 20 \\
Goniometer tilt & $\psi$ \\
Young's modulus, E $(\mathrm{GPa})$ & 210 \\
Poisson's ratio, $v$ & 0.33 \\
Number of $\psi$ angles & $13\left(\right.$ from $-36.3^{\circ}$ to $\left.+39.2^{\circ}\right)$ \\
Number of $\theta$ angles & $2\left(0^{\circ}\right.$ and $\left.90^{\circ}\right)$ \\
\hline
\end{tabular}


both treated and non-treated specimens. The results are plotted in Figure 2 against the distance from the surface; the depth hardness profile as a function of nitriding time. A maximum value of hardness of about $1100 \mathrm{HV}$ was observed near the surface within the white layer. In the diffusion layer, the hardness decreases with the distance from the surface. For depths above $0.6 \mathrm{~mm}$, the hardness remains at $355 \mathrm{HV}$. The micro hardness measurements were repeated for several specimens and no significant differences were found. Comparing the hardness of the treated and the untreated specimens for depths greater than 0.6 $\mathrm{mm}$, similar values of about $355 \mathrm{HV}$ were observed.

The metallurgical investigations carried out on the surface layer (Figure 3) and scanning electron microscopy "SEM" (Figure 4), show the existence of a compound layer, made up of two phases, $\gamma^{\prime}\left(\mathrm{Fe}_{3-4} \mathrm{~N}\right)$ and $\varepsilon\left(\mathrm{Fe}_{2-} \mathrm{N}\right)$, and a hardened diffusion layer.

Table 2 shows the change of the compound layer thickness, case depth, sur-

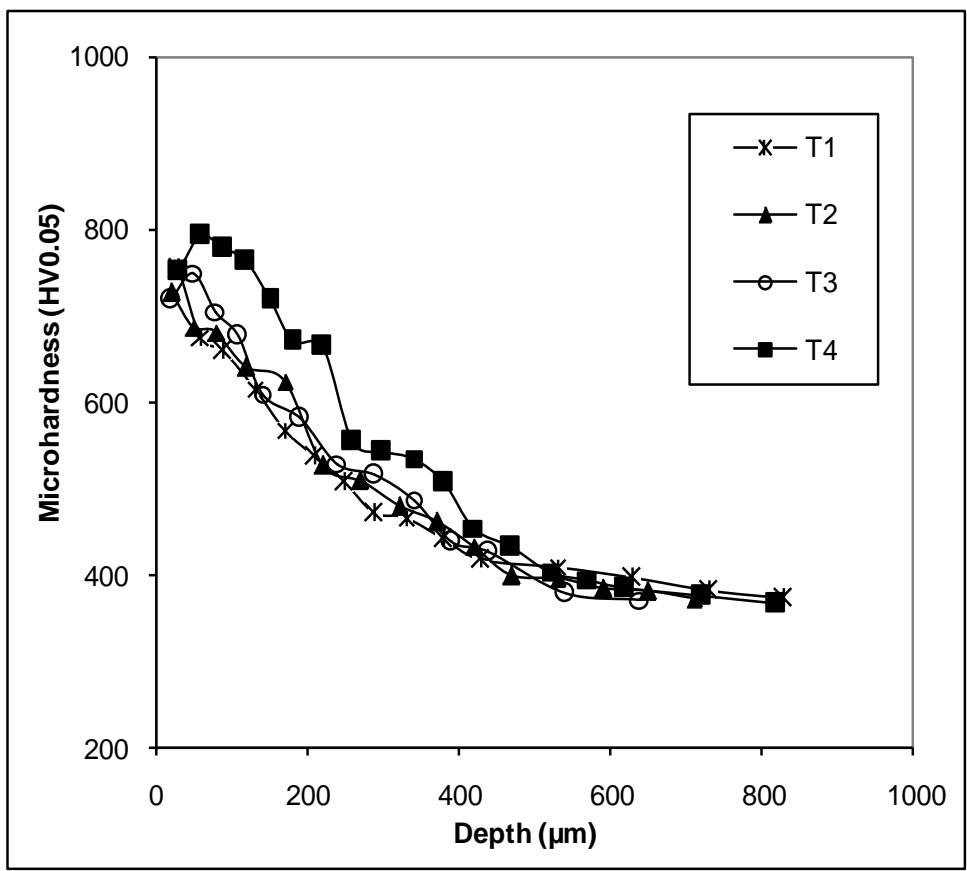

Figure 2. Variation of the microhardness according to the depth. Influence of the gas nitriding.

Table 2. Nitrided layers characteristics.

\begin{tabular}{cccccccc}
\hline \multirow{2}{*}{ State } & \multicolumn{2}{c}{ Nitriding parameters } & & & \\
\cline { 2 - 4 } & $\theta_{\mathrm{n}}\left({ }^{\circ} \mathrm{C}\right)$ & $\mathrm{t}(\mathrm{h})$ & $\tau(\%)$ & & $\mathrm{e}_{\mathrm{N}} * *(\mu \mathrm{m})$ & $\mathrm{HV}_{\text {Surf. }}$ & $\square_{\mathrm{R}}(\mathrm{MPa})$ \\
\hline $\mathrm{T} 1$ & & 12 & & 290 & 8 & 896 & -350 \\
$\mathrm{~T} 2$ & & 24 & & 330 & 11 & 1092 & -693 \\
$\mathrm{~T} 3$ & 525 & 36 & 35 & 360 & 15 & 930 & -646 \\
$\mathrm{~T} 4$ & & 48 & & 410 & 15 & 853 & -480 \\
\hline
\end{tabular}

$* \mathrm{e}_{\mathrm{N}}$ : thickness of the nitrided layer. $* \mathrm{e}_{\mathrm{C}}$ : thickness of the compound layer. 


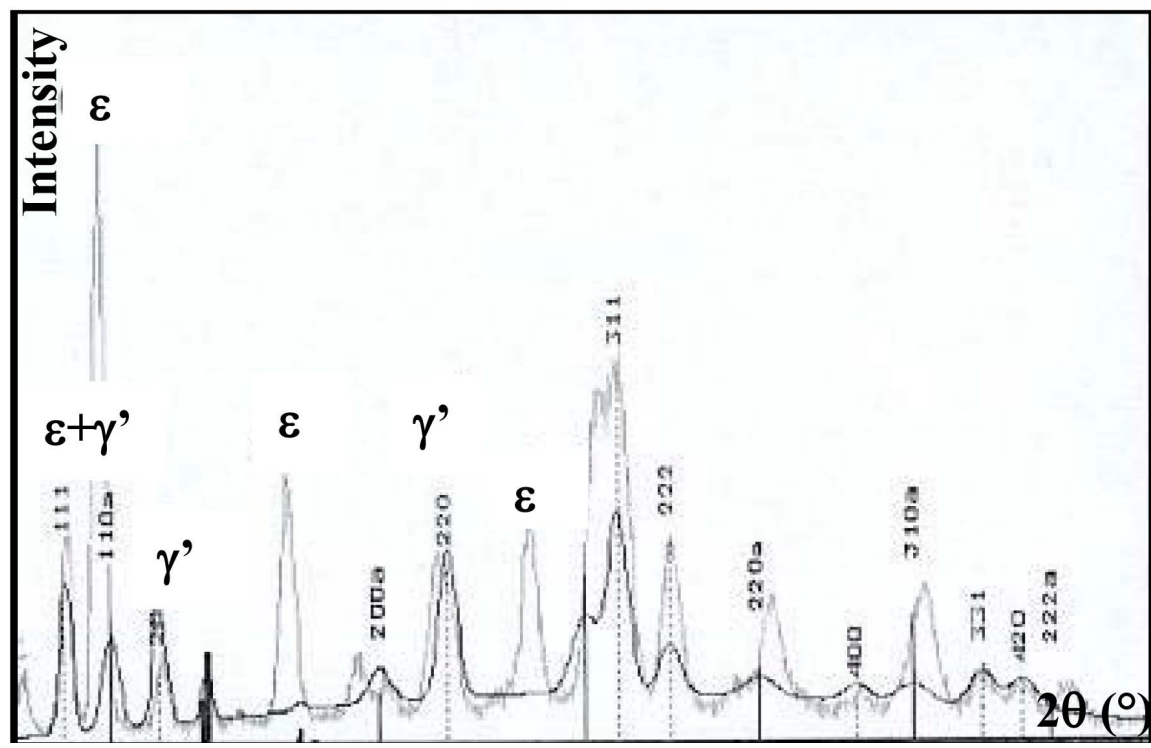

Figure 3. X-ray analysis of the surface layer.

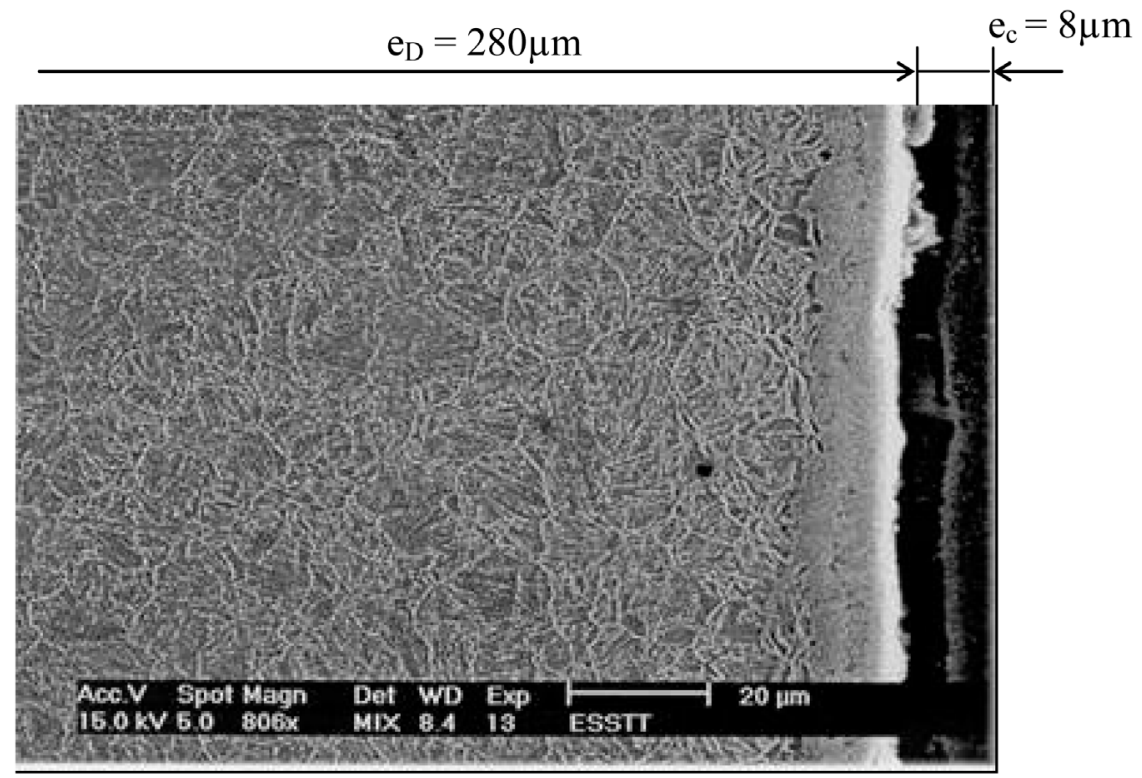

Figure 4. Metallurgical microstructure of the surface layer observed by SEM. T1 $\left(\theta_{\mathrm{n}}=\right.$ $\left.525^{\circ} \mathrm{C} ; \mathrm{t}=12 \mathrm{~h} ; \tau=35 \%\right)$.

face hardness, and surface residual stress with nitriding time. The general trend for compound layer thickness is an increase of thickness with increasing time. The case depth increases with increasing time, as expected for diffusion-controlled growth. The surface hardness of $42 \mathrm{CrMo} 4$ steel was increased up by the gas nitriding process. The maximum surface hardness was observed at a treatment time of $24 \mathrm{~h}$.

\subsection{Wear Resistance Improvement}

Results of adhesive wear tests on the $42 \mathrm{CrMo} 4$ steel, with and without gas nitriding treatments are show in Figure 5. Weight losses are less for the gas- 


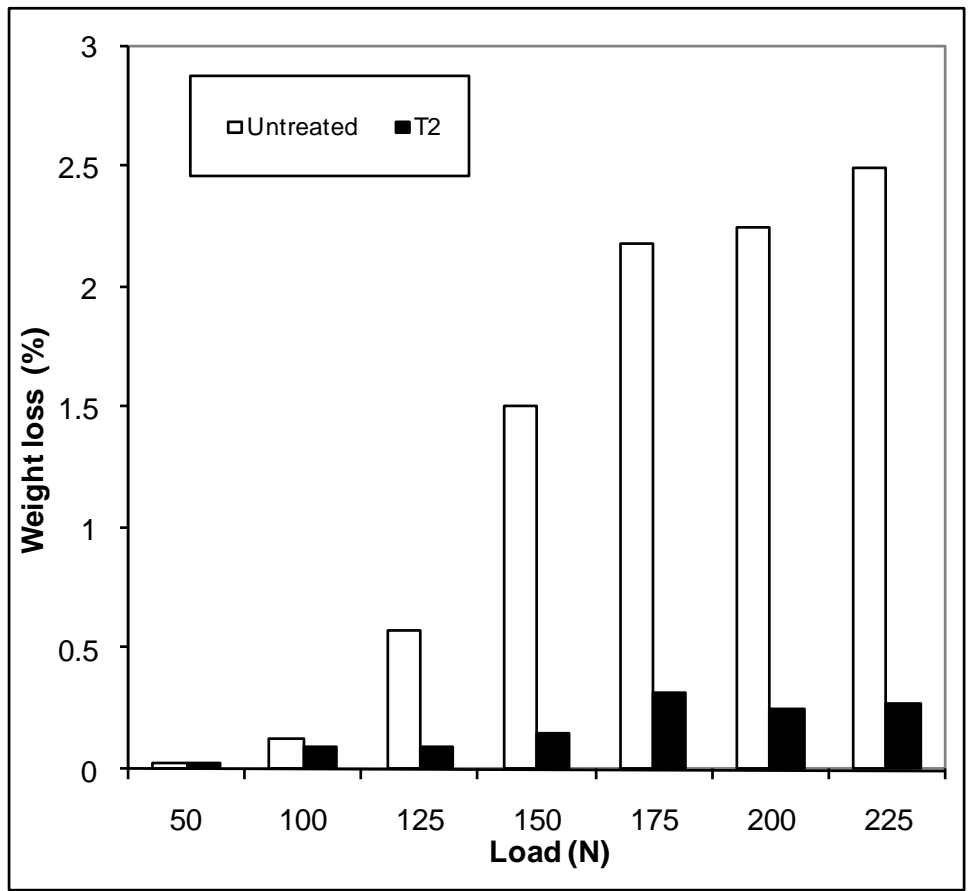

(a)

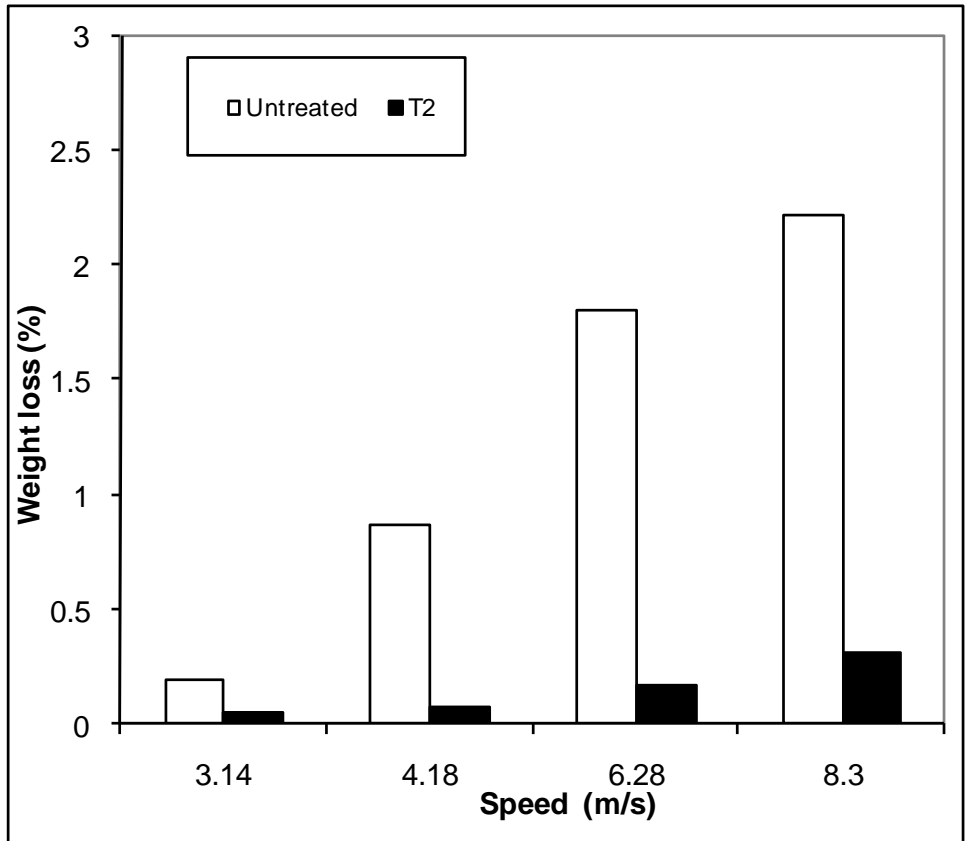

(b)

Figure 5. Weight loss as a function of tests parameters. (a) Imposed normal load $(\mathrm{F}=175 \mathrm{~N})$; (b) Imposed speed $(\mathrm{V}=8.3 \mathrm{~m} / \mathrm{s})$.

nitrided test specimens than for the quenched and tempered specimens which demonstrates the effectiveness of the gas-nitriding treatment on wear resistance. Wear resistance of the nitrided specimen was due to increased resistance against plastic deformation by increasing surface hardness. The improved wear resistance is considered to be related to the combined effect of the solid solution of 
$\mathrm{Cr}$ and the high chemical stable phases $\gamma$ and $\varepsilon$ formed on the steel surface during gas nitriding.

When it is compared to the nitrided steels in Figure 6, it is observed that the $24 \mathrm{~h}$ nitrided samples resulted in improved adhesive wear resistance than this improvement is due to the higher surface hardness values. Nitrogen atoms take interstitial places among the parent $\alpha$ structure and form surface layers by expending the lattice. The possibility of $\mathrm{CrN}$ formation increases with increasing treatment time and therefore these layers dissolve. Chromium rich oxide film formed on the surface is a continuous layer and if its thickness, intensity and adhesion are well enough, it causes an increase at the wear resistance of the specimens. Figure 7 shows results of adhesive wear test with and without compound layer. The wear loss increases with the elimination of the compound layer. It can be explained to the effects of hardness on wear. This is confirmed for all loading levels applied and for all speeds used. It has been observed that wear rate varies as a function of the tests conditions due to the presence of different wear mechanisms. Thus, for short tests conditions wear rate depends on two mechanisms: plastic deformation and adhesive wear, whereas for large tests conditions the mechanisms controlling wear rate are abrasive and oxidative wear.

\subsection{Wear Mechanisms of the Nitrided Parts}

An analysis of the wear mechanisms of the nitrided parts was carried out using SEM of the wear debris and the wear traces on the nitrided samples. The SEM observations of the wear traces on the nitrided samples made it possible to analyze the wear mechanisms on nitrided surfaces.

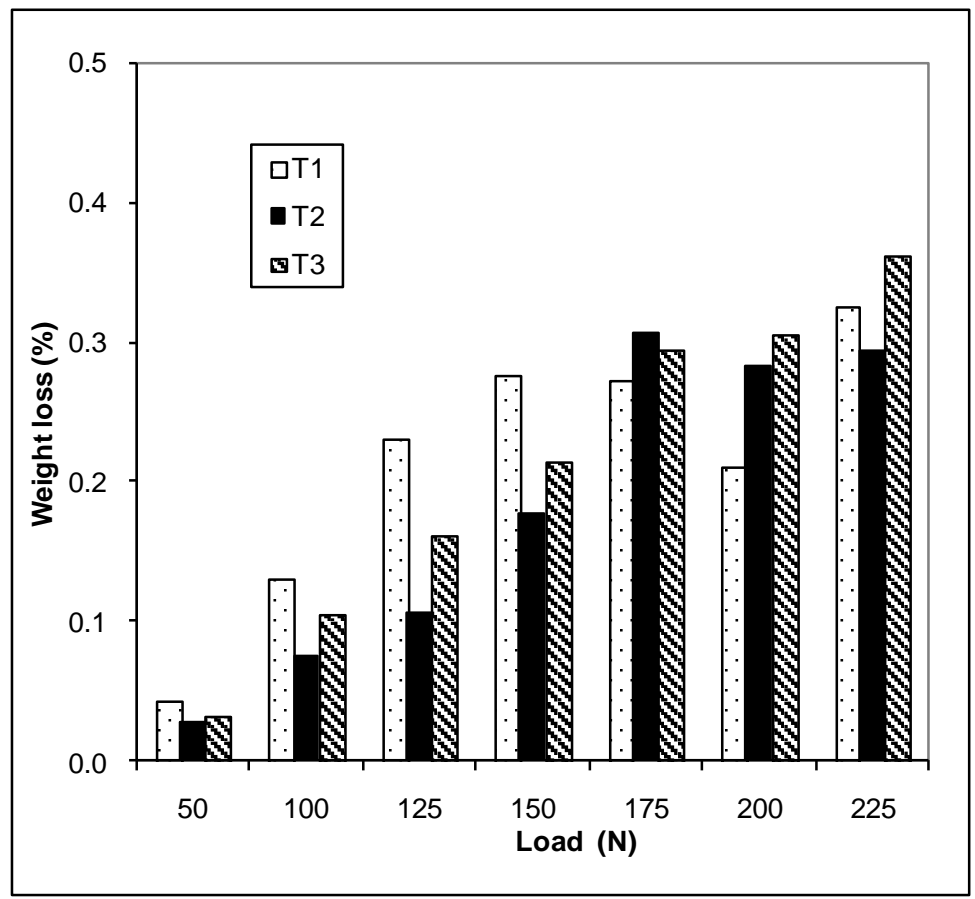

Figure 6. The wear resistance comparison of the nitrided parts. 

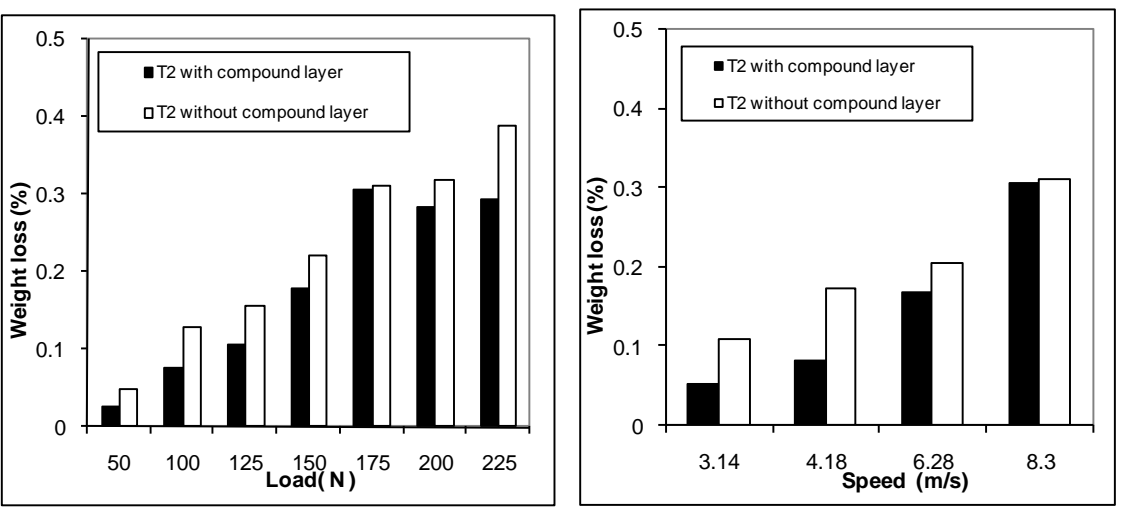

(a)
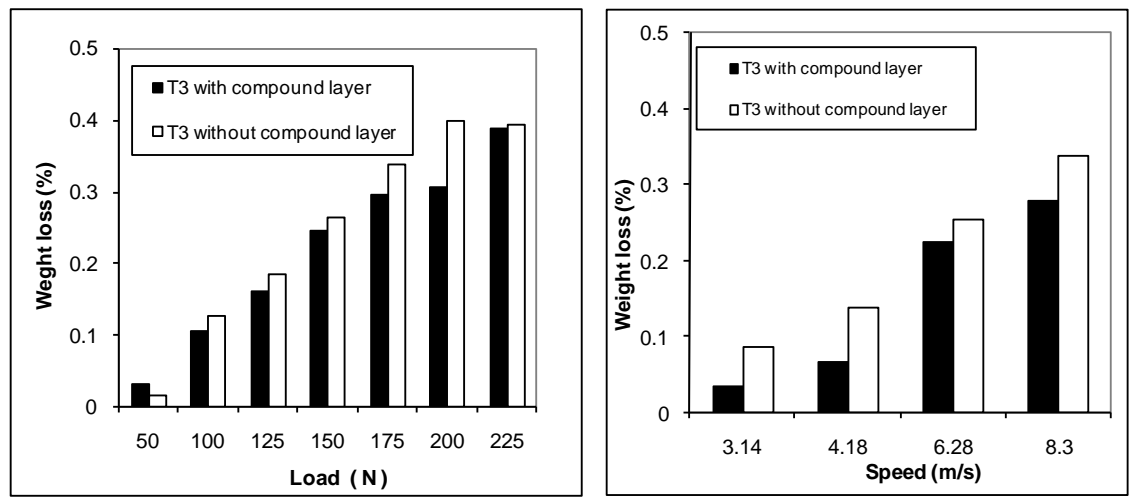

(b)

Figure 7. Influence of the layers nature: (a) T2 state (24 h); (b) T3 state (36 h).

Figure 8 shows SEM micrographs of low alloy $42 \mathrm{CrMo} 4$ steel typical worn surface. It shows wide, smooth and continuous wear grooves and flakes along the wear track, where a little metal oxide is observed. Moreover these observations highlight the existence of the phenomenon of chipping for the weak conditions of the wear tests with the appearance of micro cracks at the level of the white layer. Figure 9 shows a wear crack with a compound layer. In the initial period of sliding, the brittle compound layer with high stress fractured and then transformed into abrasive particles. Higher magnification reveals that this layer initially cracked and broke into pieces. The SEM analysis of the wear remains enabled us to note that the wear particles with compound layer are detached from scales because of the porosity and the brittleness of this layer.

These observations revealed that the compound layer is delaminated as dice during the first cycles of wear. This observation is confirmed for all the loading levels applied and for all speeds used, as illustrated in Figure 10. In this figure, one notes that the worn thickness is greater than the thickness of the compound layer even for the low loading levels. SEM images of the wear debris collected during the first cycles are presented in Figure 11. The general aspect observed shows that this debris was removed in the form of plates per delamination. It is noticed that for severe conditions the number of folds multiplies with the presence of micro cracks on the level of the compound layer. Indeed the matter re- 


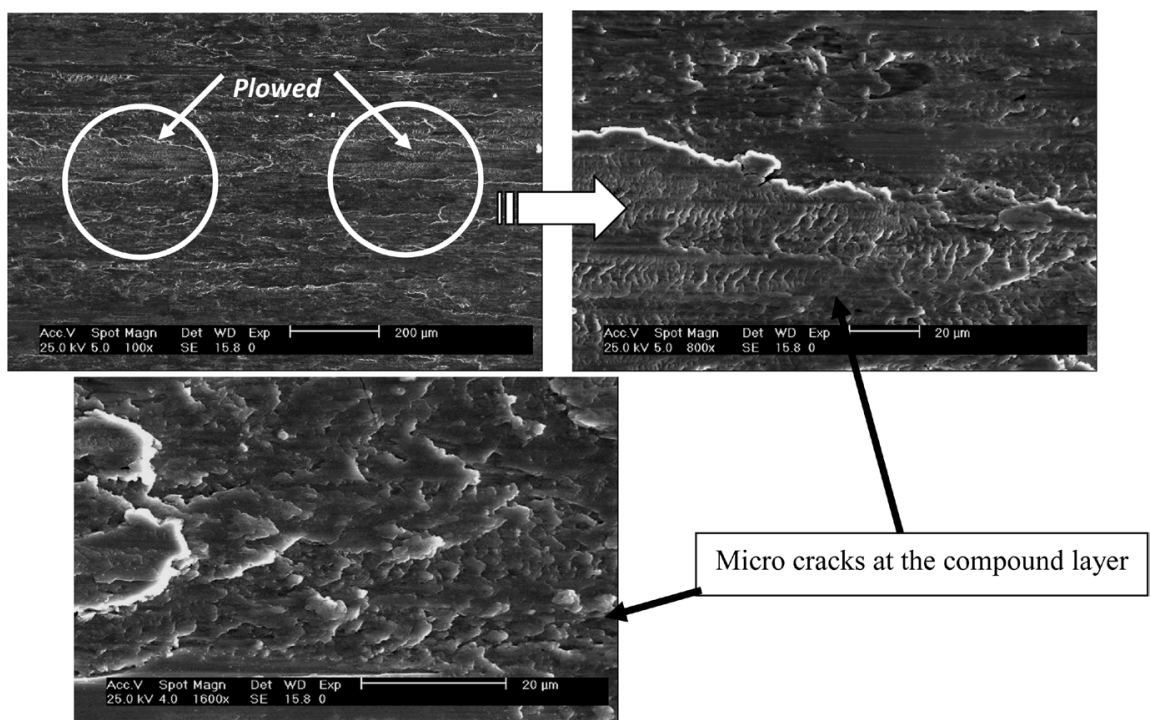

Figure 8. Wear traces morphology on nitrided surfaces. T3: $F=100 \mathrm{~N} ; \mathrm{V}=8.3 \mathrm{~m} / \mathrm{s}$.
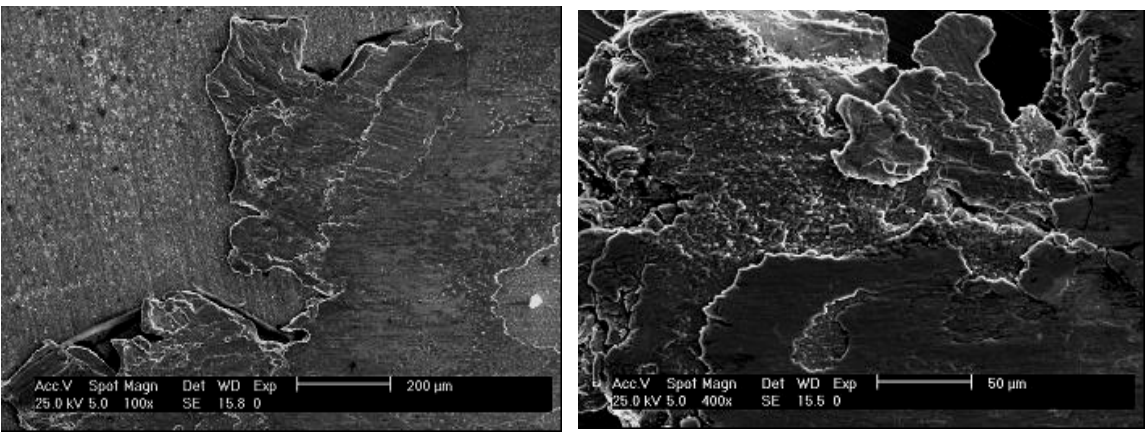

Figure 9. Wear debris composed of plastically deformed particles.
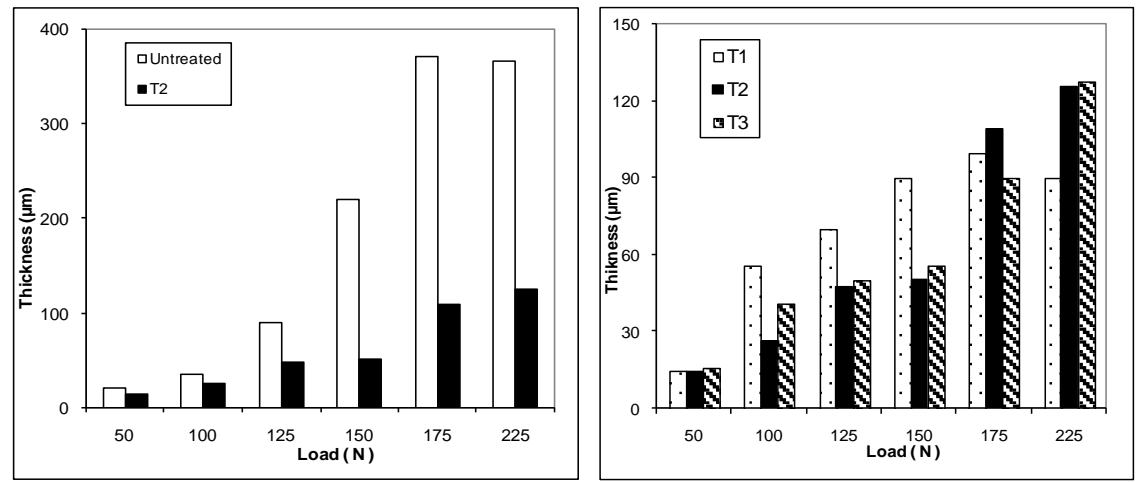

Figure 10. Variation of thickness of worn material as a function of the imposed normal load. (a) Comparison of untreated state and T2 state; (b) Comparison of the nitrided parts.

moved during the wear test is stuck on surface used creating the third body necessary to improve the wear resistance of the nitrided parts (Figure 12).

The SEM observations of the transition zone worn surfaces/no worn surfaces showed that the matter is removed in the shape of the plates by delamination. One can deduce that the compound layer has a weak adhesion with the sub- 

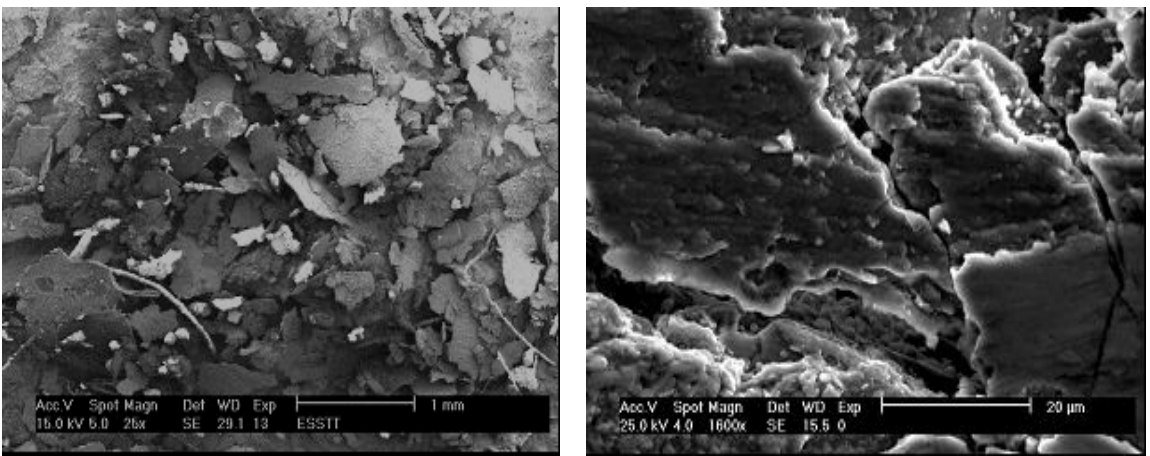

Figure 11. Morphology of the wear fragments of the compound layer collected at the beginning of the test at $\mathrm{F}=50 \mathrm{~N} ; \mathrm{V}=3.14 \mathrm{~m} / \mathrm{s}$.

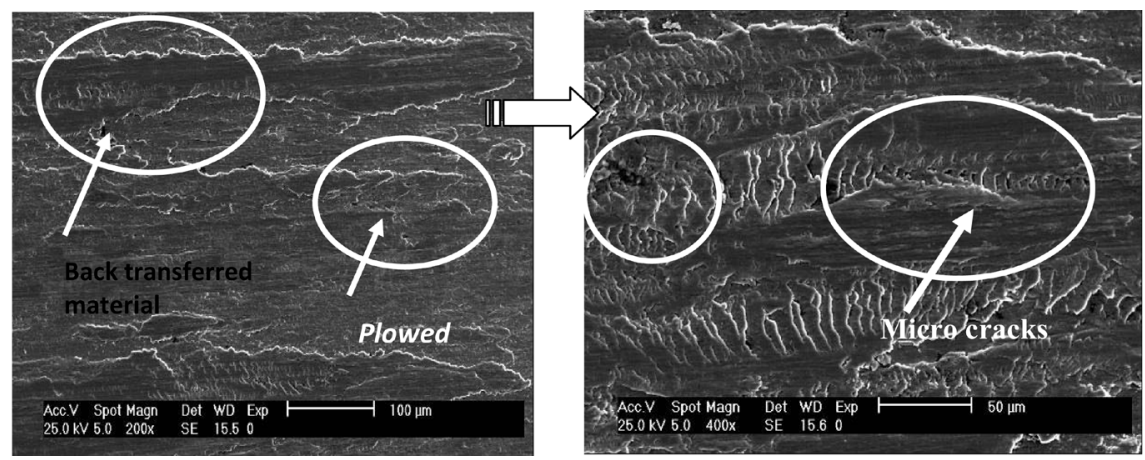

Figure 12. Multiplcation of folds in the surface used with the presence of the microscopic cracks on the compound layer (T3: $F=150 \mathrm{~N} ; \mathrm{V}=8.3 \mathrm{~m} / \mathrm{s}$ ).

strate, which can be explained by the porosity of this layer, and also its very low ductility estimated at $1 \%$. However, this low level of adhesion is only apparent when insistences of the shear stress are produced during wear (Figure 13). The SEM analysis concerning the wear morphology of the parts used under very severe conditions revealed the existence of the burns which increase according to the test condition (Figure 14). When a higher load level is applied, the dominating mechanism becomes worn by oxidation. When the compound layer was eliminated, two types of specific wear mechanisms were observed depending on the load level. The first type occurred at low load levels and corresponds to the phenomena of adhesion and abrasion as shown by SEM (Figure 15). In all cases and for the various loading levels, wear debris formed initially from the compound layer are trapped in the contact. These are composed of $\gamma$ and $\varepsilon$ iron nitrides and constitute hard particles which contribute to further wear of the diffusion layer by abrasion. In these cases the wear debris take a nodular form (Figure 16), and the worn surface presents traces of hammering (Figure 17) caused by contact between the three bodies under conditions of flow that remain difficult to control.

\section{Discussion}

The microstructure of the layer obtained by gas nitriding treatment is composed of a diffusion zone and a compound layers. Uniform and thick layers and un- 

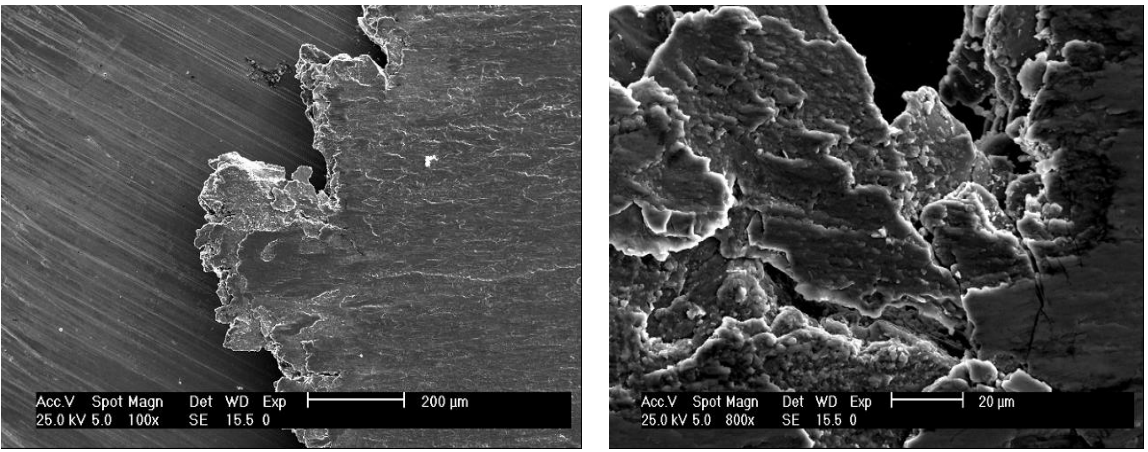

Figure 13. Transition Zone: worm surface / no worm surface.
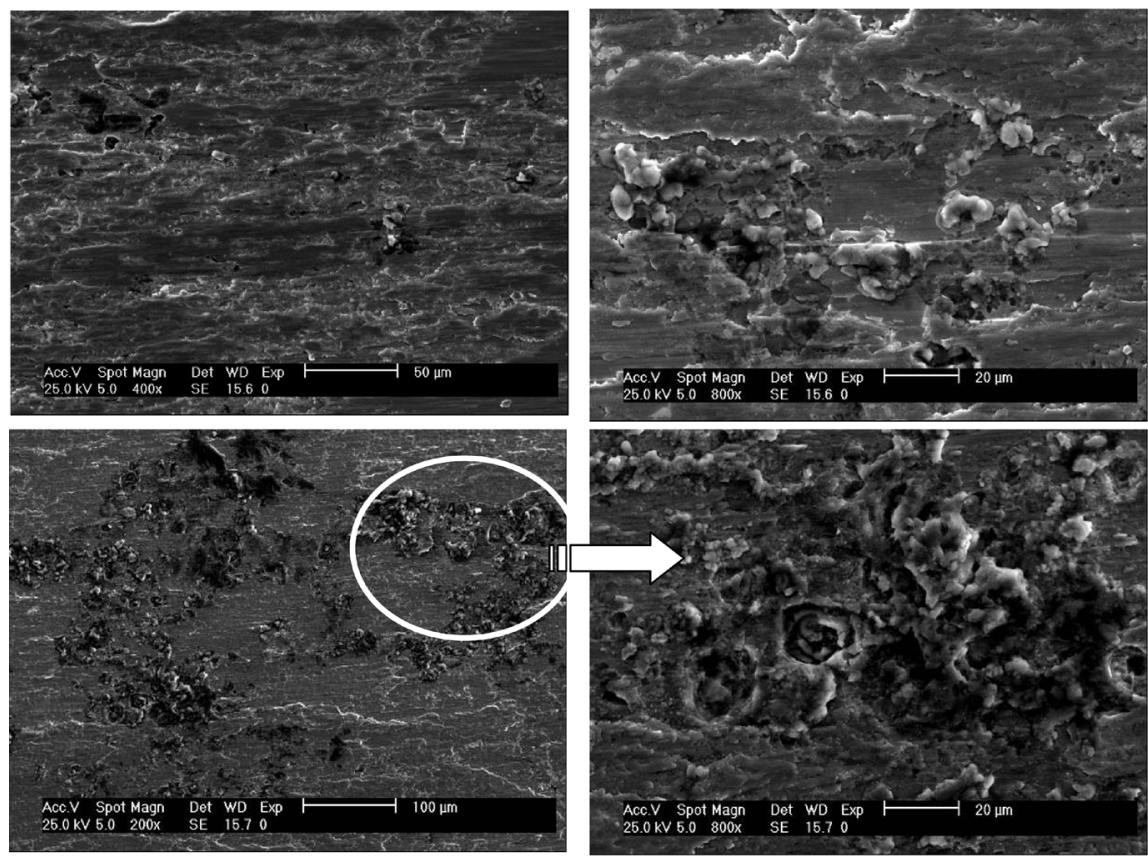

Figure 14. SEM micrographs of a worn nitrided surface after high loading levels applied. $\mathrm{T} 2: \mathrm{F}=200 \mathrm{~N} ; \mathrm{V}=8.3 \mathrm{~m} / \mathrm{s}$.

iformly distributed carbides are also observed in the nitrided layer as well as in the substrate. Metallurgically, during the nitriding process, a strengthened layer is developed in the surface and sub-surfaces of steel through the diffusion of nitrogen atoms in $\alpha$-Fe from the surface towards the substrate [2] [7] [10] [11].

The surface hardening due to the gas nitriding processes can be associated to complex and competitive mechanisms like: 1) Precipitate dispersion-hardening: hard insoluble nitrogen precipitates are incorporated into the matrix; 2) Solid solution: nitrogen in solid solution that creates a Cottrell atmosphere that locks the dislocation; 3) Surface residual stress [5] [6] [15]. At high energies, successive dissolutions and repricipitations of precipitates can occur resulting in small precipitates sizes. These small precipitates create an atmosphere-like embedded precipitates structure that contributes to the increase of the residual surface stress and results in high hardness [1] [4] [12] [15]. The micro hardness values decreased slowly with the increasing distance from the surface, but they 

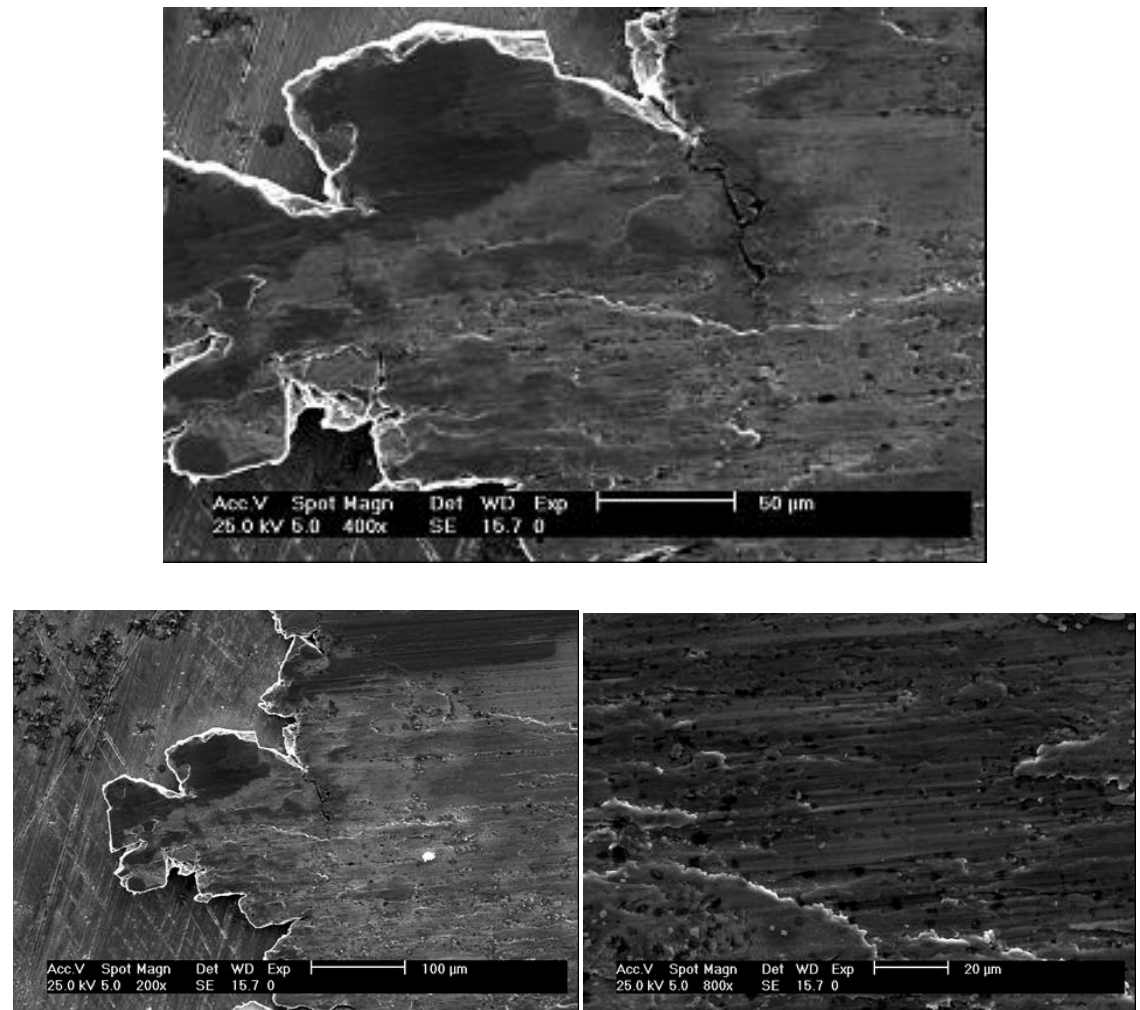

Figure 15. SEM micrograph of a worn nitrided surface after low loading levels applied. T2 without compound layer: $\mathrm{F}=100 \mathrm{~N} ; \mathrm{V}=8.3 \mathrm{~m} / \mathrm{s}$.

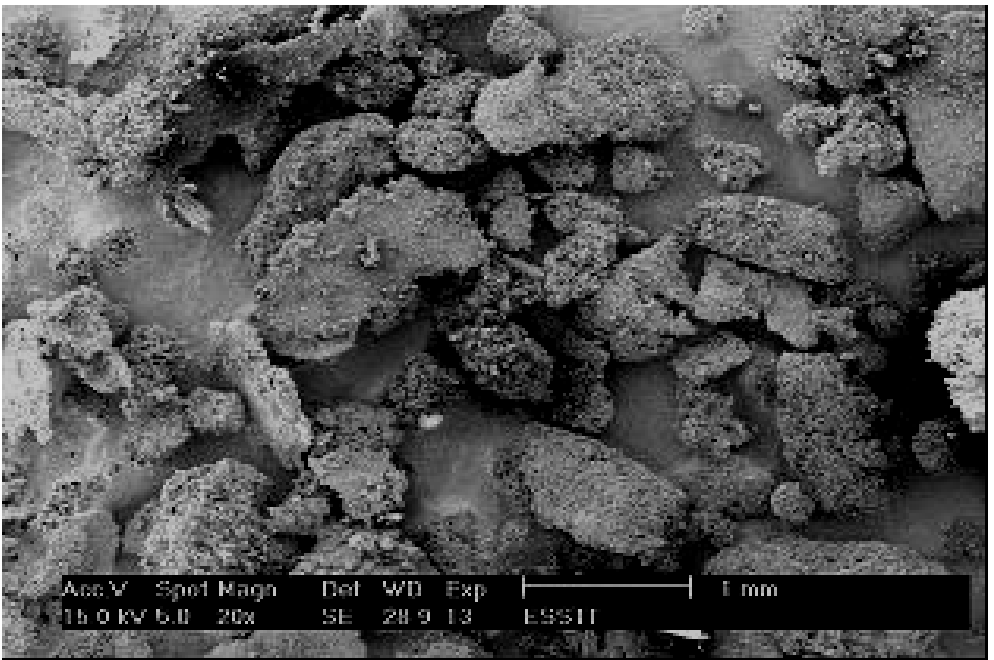

Figure 16. Morphological characteristics of the wear debris collected after high loading levels applied. T2 without compound layer: $\mathrm{F}=175 \mathrm{~N} ; \mathrm{V}=8.3 \mathrm{~m} / \mathrm{s}$.

decrease noticeably in the substrate. The maximum surface microhardness was observed in the $\mathrm{T} 2$ sample nitrided in $24 \mathrm{~h}$.

Weight losses are less for the gas ntriding test specimens than for the quenched and tempered (untreated) specimens which demonstrate the effectiveness of the gas nitriding surface treatment on wear resistance. This enhancement is due to the presence $(\mathrm{CrN})$ which increases with the increase in 


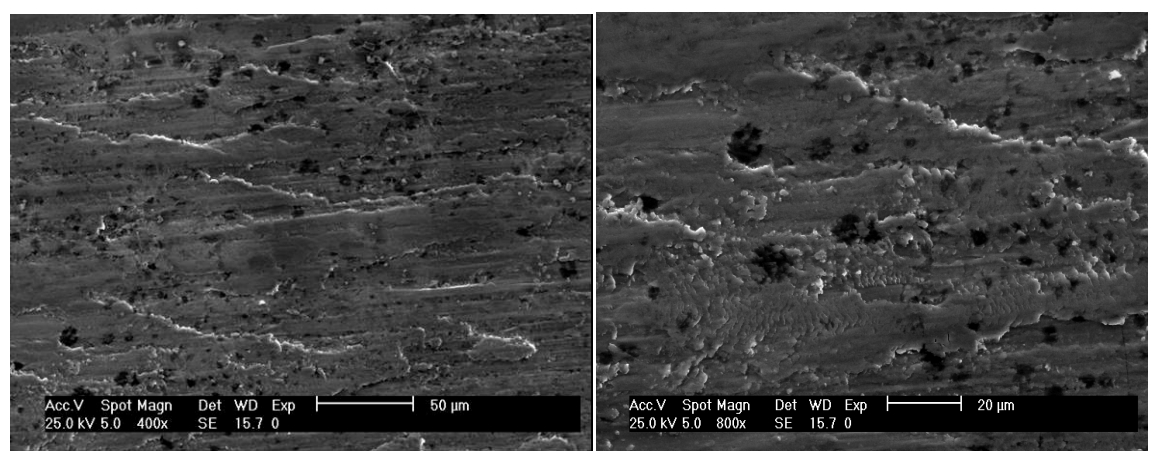

Figure 17. SEM micrographs of worn nitrided $42 \mathrm{CrMo} 4$ steel without compound layer. After high loading levels applied. T2 without compound layer: $\mathrm{F}=175 \mathrm{~N} ; \mathrm{V}=8.3 \mathrm{~m} / \mathrm{s}$.

treatment time and phases $\gamma$ and $\varepsilon$ in the compound layer which were formed during gas nitriding.

The experimental results of wear tests for the various nitrided states (T1, T2, T3 and T4), reveal that the wear resistance is closely related to the surface hardness and not the thickness of the nitrided layer. In fact, it is seemed to prove that the duration of treatment in the case of gas nitriding does not have a great influence on the wear resistance, even if there is a light variation from one state to another. The presence of a mixture phases, hard and brittle, on the surface causes an increase in wear of the nitriding specimen surface. However, this low level of adherence is only apparent when shear stresses are generated during wear. When a normal load was applied without relative movement between the bodies, the compound layer did not separate from the substrate but hammering traces were observed, the breadth of which depended on the load level [7] [9] [12] [16].

Two points can be proposed to explain the hardness effects on wear. On one hand, when oxide film was absent on the worn surface, the harder matrix revealed less abrasive due to the fact that the cracking and digging out of materials we more difficult [20] [21]. On the other hand, it can be speculated that when oxide film was formed, the harder matrix acted to support the oxide film. If hardness of steels is lower, the strengths of steel would insufficiently support oxide films, and then oxide films would be easy to fracture. By comparing the outputs, each one can note that the state T2 (nitrided during 24 hours) presents a good compromise price-wear resistance. This improvement is charged at the level of hardness higher than those of the other treatments (T1, T3 and T4). For the various studied states and for some of the test conditions the removed thickness is higher than that of the compound layer. The nitrided layer nature (compound layer + diffusion layer or diffusion layer alone) does not have a great influence on the wear resistance. Indeed, the experimental results of the tests carried out without compound layer reveal a light reduction in the wear resistance. The nitrided state with or without compound layer keeps its best wear resistance compared to the untreated state. Even if there is a relatively significant fall between hardness on the surface and under the layer (it passes from 1100 to $720 \mathrm{HV}$ ). But it remains always definitely higher than that of basic material. 


\section{Conclusions}

In the present work, the wear behaviour of $42 \mathrm{CrMo} 4$ steel has been studied according to the nitriding time used during gas nitriding. The most important conclusions obtained are:

1) Nitriding results in a considerable increase of hardness and the formation of compressive residual stress. $\mathcal{\varepsilon}\left(\mathrm{Fe}_{2+3} \mathrm{~N}\right)$ and $\gamma^{\prime}\left(\mathrm{Fe}_{4} \mathrm{~N}\right)$ nitrides are indispensable to produce the highest hardness. The nitrided case supports sufficiently the hardcoating.

2) Compared to the base line, quenched and tempered samples, adhesive wear tests demonstrated that the application of gas nitriding was effective in enhancing the hardness and adhesive wear resistance of the samples composed of the low alloy $42 \mathrm{CrMo} 4$ steel. The formation of a thin compound layer resulted in optimum wear properties. It is found that the compound layer is eliminated very quickly. It is thus vulnerable to delamination. The resulting particles constitute a third hard body which contributes to the wear by diffusion layer.

3) It is possible to obtain the desired compound of hardness, structure and thickness of the compound layer leading to optimal wear resistance of the $42 \mathrm{CrMo} 4$ steel reported here, by controlling the gas nitriding time.

4) Adhesive wear resistance increases with hardness increasing. When oxide was produced on the worn surface, the governing wear mechanism was tribooxidation, which causes less wear. On the contrary, when oxide was absent the governing wear mechanisms were abrasion and adhesion.

By referring to the experimental results of this study, the wear rate can be predicted by numerical models based on the neural network to better describe wear resistance behaviour of nitrided specimens as a function of the conditions test.

\section{Acknowledgements}

This work was performed and supported by the F3T and Manufacturing Directorate. The authors gratefully acknowledge Mr. Chokri Mbarek for his help in the support.

\section{References}

[1] Zeghni, A.E. and Hashmi, M.S.J. (2005) The Effect of Coating and Nitriding on the Wear Behaviour of Tool Steels. Journal of Materiels Processing Technology, 155156, 1918-1922.

[2] Straffelini, G., Avi, G. and Pellizzari, M. (2002) Trento: Effect of Three Nitriding Treatments on Tribological Performance of 42CrAlMo7 Steel in Boundary Lubrication. Wear, 252, 870-879.

[3] Yang, J., Liu, Y., Ye, Z., Yang, D. and He, S. (2011) Microstructural and Tribological Characterization of Plasma- and Gas-Nitrided 2Cr13 Steel in Vacuum. Materials \& Design, 32, 808-814.

[4] Binder, C., Bendo, T., Hammes, G. and Klein, A.N. and de Mello, J.D.B. (2015) Effect of Nature of Nitride Phases on Sliding Wear of Plasma Nitrided Sintered Iron. Wear, 332-333, 995-1005.

[5] Terres, M.A., Sidhom, H., Larbi, A.B.C., Ouali, S. and Lieurade, H.P. (2001) 
Influence of the Resistance to Cracking of the Compound Layer on the Fatigue Strength of the Nitrided Components. Matériaux \& Techniques, 89, 23-36. https://doi.org/10.1051/mattech/200189090023

[6] Terres, M.A., Bechouel, R. and BenMohamed, S. (2017) Low Cycle Fatigue Behaviour of Nitrided Layer of 42CrMo4 Steel. International Journal of Materials Science and Applications, 6, 18-27. https://doi.org/10.11648/j.ijmsa.20170601.13

[7] Alsaran, A. (2003) Determination of Tribological Properties of Ion-Nitrided AISI 5140 Steel. Materials Characterization, 49, 171-176.

[8] Wang, C.J. and Jaw, J.H. (2004) Study of Wear Behaviour of Nitride Layers Fe-Mn-Al-C Alloys. Surface and Coatings Technology, 177-178, 477-482.

[9] Baranowska, J., Franklin, S.E. and Pelletier, C.G.N. (2005) Tribological Behaviour and Mechanical Properties for Low Temperature Gas Nitrided. Wear, 259, 432-438.

[10] Manova, D., Hirsch, D., Richter, E., Mändl, S., Neumann, H. and Rauschenbach, B. (2007) Microstructure of Nitrogen Implanted Stainless Steel after Wear Experiment. Surface and Coatings Technology, 201, 8329-8333.

[11] Marchev, K., Cooper, C.V. and Giessen, B.C. (1998) Observation of a Compound Layer with Very Low Friction Coefficient in Ion-Nitrided Martensitic 410 Stainless Steel. Surface and Coatings Technology, 99, 229-233.

[12] Xia, Y., Wang, S., Zhou, F., Wang, H., Lin, Y. and Xu, T. (2006) Tribological Properties of Plama Nitrided Stainless Steel against SAE52100 Steel under Ionic Liquid Lubrication Condition. Tribology International, 39, 635-640.

[13] Terres, M.A., Sidhom, H., Larbi, A.B.C. and Lieurade, H.P. (2003) Fatigue Behaviour of an Ion Nitrided Steel. Annales de Chimie Science des Materiaux, 28, 25-41.

[14] Baranowska, J., Franklin, S.E. and Kochmanska, A. (2007) Wear Behaviour of LowTemperature Gas Nitrided Austenitic Stainless Steel in a Corrosive Liquid Environment. Wear, 263, 669-673.

[15] Kuksenova, L.I. and Michugina, M.S. (2008) Effect of Heating Conditions in Nitriding on the Structure and Wear Resistance of Surface Layers of Steel 38Kh2MyuA. Metal Science and Heat Treatment, 50, 68-72. https://doi.org/10.1007/s11041-008-9013-8

[16] Zambrano, O.A., Aguilar, Y., Valdés, J., Rodríguez, S.A. and Coronado, J.J. (2016) Effect of Normal Load on Abrasive Wear Resistance and Wear Micromechanisms in FeMnAlC Alloy and Other Austenitic Steels. Wear, 348-349, 61-68.

[17] Larbi, A.B.C., Cherif, A. and Tarres, M.A. (2005) Improvement of the Adhesive Wear Resistance of Steel by Nitriding Quantified by the Energy Dissipated in Friction. Wear, 258, 712-718.

[18] Zheng, C., Liu, Y., Wang, H., Zhu, H., Ji, R., Liu, Z. and Shen, Y. (2015) Research on the Effect of Gas Nitriding Treatment on the Wear Resistance of Ball Seat Used in Multistage Fracturing. Materials \& Design, 70, 45-52.

[19] Park, Y.G., Wey, M.Y. and Hong, S.I. (2007) Enhanced Wear and Fatigue Properties of Ti-6Al-4V Alloy Modified by Plasma Carburizing. Journal of Materials Science Materials in Medicine, 18, 925-931. https://doi.org/10.1007/s10856-006-0014-0

[20] Torres, H., Varga, M., Adam, K. and Rodríguez Ripoll, M. (2016) The Role of Load on Wear Mechanisms in High Temperature Sliding Contacts. Wear, 364-365, 73- 83.

[21] Li, G.Y., Wang, Z.Y. and Lei, M.K. (2012) Transition of Wear Mechanisms of Plasma Source Nitrided AISI 316 Austenitic Stainless Steel against Ceramic Counterface. Journal Tribology, 134, Article ID: 011601.

https://doi.org/10.1115/1.4005516 
Submit or recommend next manuscript to SCIRP and we will provide best service for you:

Accepting pre-submission inquiries through Email, Facebook, LinkedIn, Twitter, etc. A wide selection of journals (inclusive of 9 subjects, more than 200 journals)

Providing 24-hour high-quality service

User-friendly online submission system

Fair and swift peer-review system

Efficient typesetting and proofreading procedure

Display of the result of downloads and visits, as well as the number of cited articles Maximum dissemination of your research work

Submit your manuscript at: http://papersubmission.scirp.org/

Or contact msa@scirp.org 